\title{
The Role of the Anode Material in Selective Penicillin G Oxidation in Urine
}

\author{
Salvador Cotillas, ${ }^{[a]}$ Engracia Lacasa, ${ }^{[a]}$ Miguel Herraiz, ${ }^{[a]}$ Cristina Sáez $^{*[b]}$ Pablo Cañizares, ${ }^{[b]}$ \\ and Manuel A. Rodrigo ${ }^{[b]}$
}

In this work, the removal of antibiotic penicillin $\mathrm{G}$ by electrolysis with boron doped diamond (BDD) and mixed metal oxide (MMO) anodes in urine media is evaluated. First, electrolysis in different water matrices (sulfate, chloride and urine) were carried out with diamond anodes to shed light on the contribution of mediated mechanisms. Results showed that penicillin $\mathrm{G}$ was completely removed by electrolysis for electric charges below $5 \mathrm{Ah} \mathrm{dm}^{-3}$, regardless of the water matrix and the current density applied $\left(10-100 \mathrm{mAcm}^{-2}\right)$. Then, the influence of the anode material was evaluated for the degradation of penicillin $\mathrm{G}$ in urine media. A complete removal of the antibiotic was attained, regardless of the tested anode material, although the BDD anode was found to be more efficient than MMO. Results also showed that, at the current charges in which the antibiotic is depleted, the removal of other organics was much lower and the formation of chlorates was negligible, especially operating at low current densities. Because of this selective oxidation of the pharmaceutical compound, electrolysis can be proposed to be used as a pretreatment technology for later and cheaper biological treatment.

\section{Introduction}

Thousands of pharmaceuticals are used around the World and an important amount may reach the environment. Antibiotics, antidepressants, anti-inflammatories, analgesics, beta-blockers, oral contraceptives and hormones totalize, by far, the biggest contribution into the environment, due to their excretion in urine or feces from humans and, some of them, from animals. Many pharmaceuticals may be considered as non-biodegradable organic compounds and, consequently, their degradation is not achieved by the biological treatments from the conventional urban wastewater treatments plants (UWWTPS). Hence, they are discharged into the environment, causing an emerging and very serious environmental problem due to their hazardousness for both, aquatic ecosystems and human health. ${ }^{[1]}$

In hospital wastewater, pharmaceuticals can be present at higher concentration than in urban wastewater or in surface water resources due to dilution effect undergone by this flow in urban sewers. ${ }^{[2]}$ Thus, hospital effluents are currently discharged and mixed with urban and/or industrial wastewater flows into UWWTPs due to inexistence of legal regulations. ${ }^{[3]}$ Among the effluents generated in a hospital, human urine contributes

[a] Dr. S. Cotillas, Dr. E. Lacasa, M. Herraiz

Department of Chemical Engineering

School of Industrial Engineering

University of Castilla-La Mancha

02071 Albacete, Spain

[b] Dr. C. Sáez, Prof. P. Cañizares, Prof. M. A. Rodrigo

Department of Chemical Engineering

Faculty of Chemical Sciences and Technologies

University of Castilla-La Mancha

13005 Ciudad Real, Spain

fax: + 34-926-29-52-56

E-mail: cristina.saez@uclm.es

An invited contribution to a Special Collection dedicated to Trends in Synthetic Diamond for Electrochemical Applications around $2-3 \%$ in volume. However, urine may be considered one of the main sources of contamination, because in this matrix pharmaceutical products, their metabolites and pathogens may be greatly concentrated. ${ }^{[4]}$ Thus, the efficient management of urine would be an important challenge for reducing the environmental and health impact of hospital effluents in origin.

In this way, penicillin $G$ is an important beta-lactam antibiotic which is among the most frequently used antibiotics in medical practice, due to their antibacterial activity by associated to the disruption of the synthesis of bacterial cell walls. ${ }^{[5]}$ Thus, penicillin $\mathrm{G}$ is used to treat many different types of severe infections, including strep and staph infections, diphtheria, meningitis, gonorrhea or syphilis. ${ }^{[6]}$ This antibiotic is mainly excreted unchanged and conventional treatments of WWTPs cannot degrade penicillin G efficiently. Because of that, it is necessary to look for alternative treatments. In recent studies, several physical-chemical methods, such as chemical oxidation by persulfates, ${ }^{[7]}$ catalytic processes ${ }^{[5 b, 8]}$ or advanced oxidation processes (AOPs) ${ }^{[9]}$ have shown their ability to remove penicillin $\mathrm{G}$.

Within this later group of technologies, electrochemical oxidation (EO) is widely reported for its great efficiency and robustness on the degradation of effluents containing organic pollutants not only pharmaceuticals but also alcohols, carboxylic acids or even more complex aromatic hydrocarbons such as dyes. ${ }^{[10]}$ Use of diamond coatings as electrodes leads to a very efficient process, which promotes the mineralization of molecules that are refractory for other treatments. Because of these good prospects, degradation of organics contained in urine has been studied in previous works using conductive diamond electrochemical oxidation. ${ }^{[10 d, 11]}$ In general terms, it was observed that complete mineralization of the organic load can be attained but the formation of chlorates and perchlorates could 
not be prevented, although some indications were proposed to minimize this contribution.

As it is known, the efficiency of the electrochemical processes depends on the waste composition (nature and concentration of the organic pollutant and supporting electrolyte) and also on the anode material and operating conditions (mainly, current density). ${ }^{[12]}$ Attending to the role of the anode material, the electrocatalytic properties of different anode materials lead to total or partial mineralization of organic pollutants depending on the action of the so-called physisorbed or chemisorbed hydroxyl radicals. Likewise, the inorganic salts present in the raw wastewater influences can also be very relevant because during the treatment, they can also be transformed into powerful oxidants such as persulfates, peroxodiphosphates, oxochlorinated anions and/or hydrogen peroxide which may significantly contribute to the degradation of organic pollutants. ${ }^{[13]}$ However, this oxidant production is related to the anode material used and thus, this makes the selection of the electrode material a key point of the electrochemical treatment.

With this background, the present work aims to shed light on the role of mediated oxidation during the removal of antibiotic penicillin $G$ in urine by electrochemical oxidation. Urine can be considered as a very complex matrix in which organic compounds and inorganic salts coexist, and thus, the chemistry and electrochemistry of the system is quite intricate. For this reason, to try to elucidate the role of the different oxidation mechanism, electrolysis in synthetic sulfate and chloride aqueous solutions were also carried out. Likewise, the influence of the current density $\left(10-100 \mathrm{mAcm}^{-2}\right)$ and the anode material (Boron Doped Diamond, BDD and Metal Mixed Oxide, MMO) was evaluated on penicillin $G$ removal due to these parameters show a significant contribution on the production of powerful oxidants ${ }^{[13 a]}$ and, hence, it is expected a marked influence on the process performance by mediated oxidation, as occur during the treatment of wastewater polluted with other organics. ${ }^{[14]}$

\section{Experimental Section}

\section{Chemicals}

Penicillin G, sodium chloride, sodium sulfate and urine compounds ${ }^{[11,15]}$ were of analytical grade from Sigma-Aldrich. Other chemicals employed in several analyses were also analytical grade and purchased from Sigma-Aldrich. Each solution was prepared with double deionized water obtained from a Millipore Milli-Q system, with resistivity $18.2 \mathrm{M} \Omega \mathrm{cm}$ at $25^{\circ} \mathrm{C}$.

\section{Experimental Procedures}

Electrolysis experiments were carried out in a single compartment electrochemical cell working under batch-operation mode. ${ }^{[16]}$ Boron Doped Diamond (BDD, purchased from WaterDiam) and Mixed Metal Oxide ( $\mathrm{MMO}$ based on $\mathrm{RuO}_{2} / \mathrm{Ti}$, purchased from Tianode) with a circular geometric area of $78 \mathrm{~cm}^{2}$ were used as anode materials, and the inter-electrode gap between both electrodes was
$9 \mathrm{~mm}$. The electric current was provided by a Delta Electronika ES030-10 power supply (0-30 V, 0-10 A).

Synthetic wastewater was prepared with $100 \mathrm{mg} \mathrm{dm}^{-3}$ of penicillin $\mathrm{G}$ in several water matrices. The water matrices consist of aqueous solutions with $2000 \mathrm{mg} \mathrm{dm}^{-3} \mathrm{Na}_{2} \mathrm{SO}_{4}, 2000 \mathrm{mg} \mathrm{dm}^{-3} \mathrm{NaCl}$ and synthetic urine $\left(3333.33 \mathrm{mg} \mathrm{dm}^{-3}\right.$ urea; $166.67 \mathrm{mg} \mathrm{dm}^{-3}$ creatinine, $50 \mathrm{mg} \mathrm{dm}^{-3}$ uric acid and inorganic salts). ${ }^{[15]}$ All experiments were carried out under galvanostatic conditions and the current densities applied were 10 and $100 \mathrm{~mA} \mathrm{~cm}^{-2}$. These values of current densities were proposed as boundary cases of study, in which direct or mediated oxidation is expected to be promoted. ${ }^{[20]}$ The synthetic wastewater was stored in a $1 \mathrm{dm}^{3}$ glass tank and samples of $50 \mathrm{~mL}$ were collected to analyze organic compounds, TOC, inorganic ions and oxidants.

\section{Analytical Procedures}

Penicillin $\mathrm{G}$ was determined by high performance liquid chromatography (HPLC) with an Agilent 1200 series coupled a DAD detector. A ZORBAX Eclipse Plus C18 analytical column was used and its temperature was maintained at $30^{\circ} \mathrm{C}$. The mobile phase consisted of $50 \%$ acetonitrile $/ 50 \%$ Milli-Q water by applying a flow rate of $0.8 \mathrm{~cm}^{3} \mathrm{~min}^{-1}$, an injection volume of $20 \mu \mathrm{L}$ and a DAD detection wavelength of $220 \mathrm{~nm}$.

The inorganic ions were determined by ion chromatography (IC) with a Metrohm 930 Compact IC Flex coupled to a conductivity detector. Anions were analyzed by using the column Metrosep A Supp 7 with a mobile phase of $85: 15 \mathrm{v} / \mathrm{v} 3.6 \mathrm{mmoldm}^{-3} \mathrm{Na}_{2} \mathrm{CO}_{3} /$ acetone and a flow rate of $0.8 \mathrm{~cm}^{3} \mathrm{~min}^{-1}$. Moreover, cations were analyzed by using the column Metrosep C6 250 with a mobile phase of $1.7 \mathrm{mmol} \mathrm{dm}^{-3} \mathrm{HNO}_{3}$ and $1.7 \mathrm{mmol} \mathrm{dm}^{-3}$ 2,6-pyridinedicarboxylic acid and a flow rate of $0.9 \mathrm{~cm}^{3} \mathrm{~min}^{-1}$. The volume injection was $20 \mu \mathrm{L}$.

The organic compounds from urine were determined by HPLC (uric acid), IC (creatinine) and colorimetric methods (urea). Uric acid was determined with HPLC by using a mobile phase consisted of $2 \%$ acetonitrile/ $98 \%$ aqueous solution with $0.1 \%$ of formic acid, applying a flow rate of $1.0 \mathrm{~cm}^{3} \mathrm{~min}^{-1}$, an injection volume of $10 \mu \mathrm{L}$ and a DAD detection wavelength of $292 \mathrm{~nm}$. The urea was determined by a spectrophotometric method using the Biochrom Libra S50 UV-Vis Spectrophotometer and this method is based upon the yellow-green color produced when p-dimethylaminobenzaldehyde is added to urea in dilute hydrochloric acid solution. ${ }^{[17]}$

The Total Organic Carbon (TOC) was determined using a Shimadzu TOC-VCPH analyser. Hypochlorite was analyzed by titration with $0.001 \mathrm{moldm}^{-3} \mathrm{As}_{2} \mathrm{O}_{3}$ in $2 \mathrm{moldm}^{-3} \mathrm{NaOH}^{[18]}$ Oxidants were determined iodometrically according to Kolthoff \& Carr. ${ }^{[19]}$ The $\mathrm{pH}$ and conductivity were simultaneously measured using a Sension + MM150 Portable Multi-Parameter Meter from HACH.

\section{Results and Discussion}

Figure 1 shows changes in penicillin $\mathrm{G}$ concentration during the conductive diamond electrolysis of $100 \mathrm{mg} \mathrm{dm}^{-3}$ of the antibiotic in urine media and in sulfate and chloride aqueous solutions, at two current densities (10 and $100 \mathrm{mAcm}^{-2}$ ). In all cases, experimental data fitted to a first order kinetics ( $\mathrm{Ln}(\mathrm{C} / \mathrm{Co})$ vs. time). For comparison purposes, the resulted kinetic constants are plotted in the onset of the figure. 


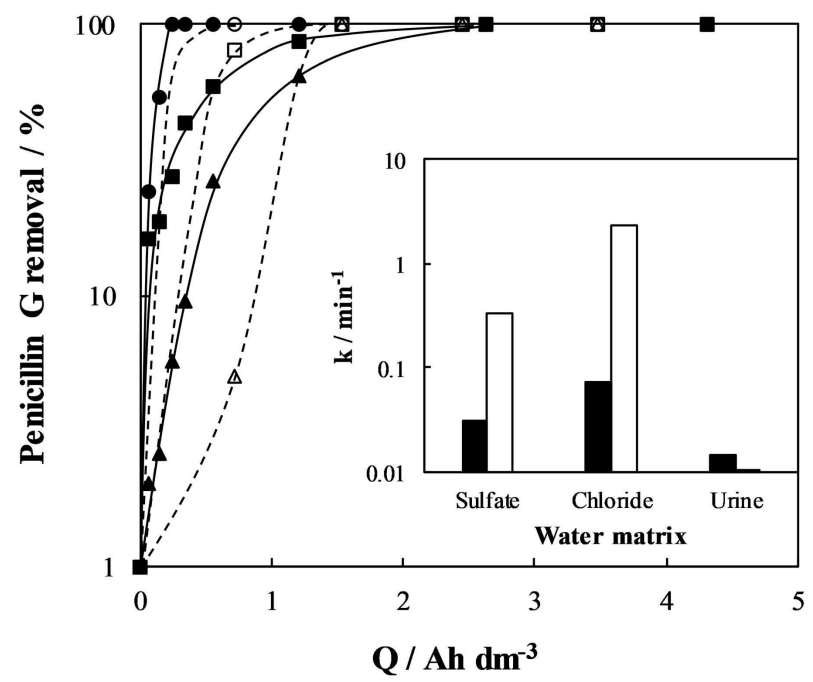

Figure 1. Influence of the current density on penicillin $\mathrm{G}$ removal as function of the applied electric charge during the electrolysis with diamond anodes.

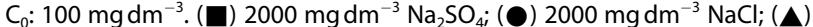
urine. Black symbols: $10 \mathrm{mAcm}^{-2}$; white symbols $100 \mathrm{mAcm}^{-2}$.

As can be observed, the complete antibiotic removal was obtained in all the experimental conditions tested although the specific charge required for the complete oxidation depends on both supporting media and current density. The removal efficiency is higher in chloride media followed by sulfate and finally, urine media. In this point, it is important to highlight the complexity of the urine matrix, in which other organic compounds (urine, creatinine and uric acid) are contained in higher concentration than penicillin $G$. These organics can be also oxidized during the treatment, consuming electrons and thus decreasing the antibiotic removal efficiency. ${ }^{[15,21]}$ Figure 2 shows the removal percentage of these organic after passing electric charge required to attain the complete removal of penicillin G: $1.5 \mathrm{Ahdm}^{-3}$ at $10 \mathrm{mAcm}^{-2}$ and $2.5 \mathrm{Ahdm}^{-3}$ at

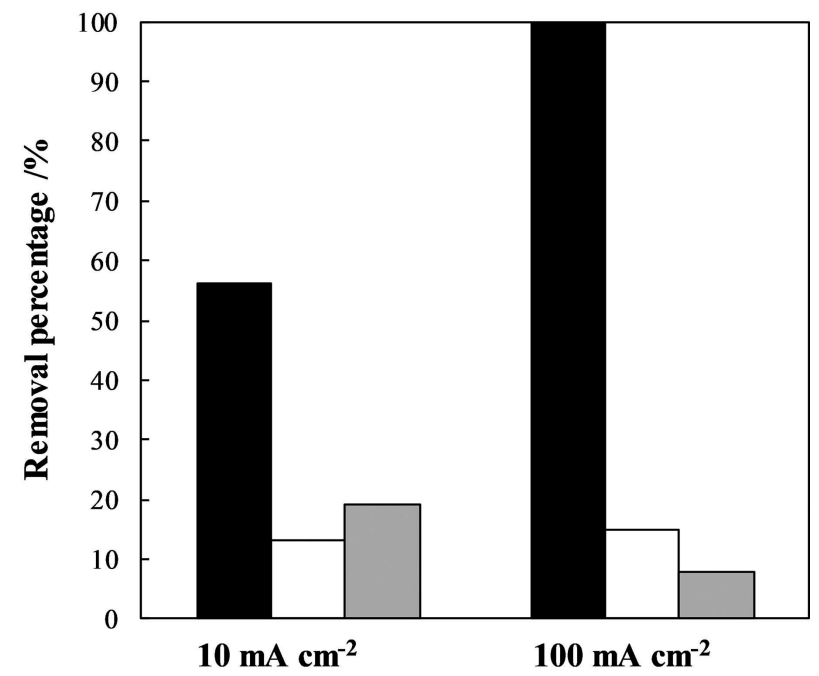

Figure 2. Removal percentage of uric acid ( $\square$ ), urea ( $\square$ ) and creatinine ( $\square$ ) during the electrolysis of penicillin $\mathrm{G}$ solutions in urine media. Electric charge passed: $1.5 \mathrm{Ah} \mathrm{dm}^{-3}$ at $10 \mathrm{~mA} \mathrm{~cm}^{-2}$ and $2.5 \mathrm{Ah} \mathrm{dm}^{-3}$ at $100 \mathrm{mAcm}^{-2}$.
$100 \mathrm{mAcm}^{-2}$. As it can be observed, uric acid is the most efficiently removed, whereas urea and creatinine remain in the solutions in highly relevant concentrations. Results shown in the Figure 2 are very important, because they support than in the competitive oxidation of organics, the antibiotic is degraded first, and this opens the possibility of selective treatments in which the electrochemical technology is only used to reduce the concentration of these hazardous species, what it could be attained with low current charge passed (and hence operation cost treatments). Then, the effluent of this electrochemical pretreatment may follow other cheaper treatments in safer conditions, in which the remaining organic compounds contained in urine may be depleted.

On the other hand, urine media is also constituted by a mixture of inorganic salts $\left(1000 \mathrm{mg} \mathrm{dm}^{-3}\right.$ of potassium chloride, $170 \mathrm{mg} \mathrm{dm}^{-3}$ of magnesium sulfate, $166.67 \mathrm{mg} \mathrm{dm}^{-3}$ of sodium carbonate, $83.34 \mathrm{mg} \mathrm{dm}^{-3}$ of diammonium hydrogen phosphate and $28.34 \mathrm{mgdm}^{-3}$ of calcium phosphate) ${ }^{[11,21]}$ that can be transformed into oxidants, as reported during the electrolysis of synthetic chloride, sulfate or phosphate solutions. ${ }^{[2]}$ In chloride media, significant amounts of hypochlorite can be produced from the electro-oxidation of chlorides [Equations (1)-(3)] whereas persulfate is generated when working in sulfate media [Equation (4)].[13a] In urine media, besides hypochlorite and persulfate, the oxidation of the phosphates and carbonates can lead to the formation peroxodiphosphate [Equation (5)] and percarbonates [Equation (6)], respectively. The oxidation potential of them differs but, in higher or lesser extension, they can react with the organics and thus, contribute to the degradation of the antibiotic (mediated oxidation). ${ }^{[23]}$

$2 \mathrm{Cl}^{-} \rightarrow \mathrm{Cl}_{2}+2 \mathrm{e}$

$\mathrm{Cl}_{2}+\mathrm{H}_{2} \mathrm{O} \rightarrow \mathrm{HClO}+\mathrm{Cl}^{-}+\mathrm{H}^{+}$

$\mathrm{HClO} \rightleftharpoons \mathrm{H}^{+}+\mathrm{ClO}^{-}$

$2 \mathrm{SO}_{4}{ }^{2-} \rightarrow \mathrm{S}_{2} \mathrm{O}_{8}{ }^{2-}+2 \mathrm{e}$

$2 \mathrm{PO}_{4}{ }^{3-} \rightarrow \mathrm{P}_{2} \mathrm{O}_{8}{ }^{4-}+2 \mathrm{e}$

$2 \mathrm{CO}_{3}{ }^{2-} \rightarrow \mathrm{C}_{2} \mathrm{O}_{6}{ }^{2-}+2 \mathrm{e}^{-}$

The lower efficiency observed in the degradation of penicillin $G$ in urine media may be related to the competitive oxidation of urea and other organics present in the solutions. However, it is reported that oxidants formed may also react among them, especially when they are massively generated. Then, they are not available to react with organics and the efficiency of the degradation process decreases. ${ }^{[12]}$

The production of oxidants, as well as, the removal of organics is clearly influenced by the current density. To evaluate its effect, two different scenarios were selected: low current density $\left(10 \mathrm{~mA} \mathrm{~cm}^{-2}\right)$, at which mediated oxidation is not expected to be the main oxidation mechanism and high current density $\left(100 \mathrm{~mA} \mathrm{~cm}^{-2}\right)$, at which the formation of oxidants is promoted. ${ }^{[24]}$ In general, it can be observed that the efficiency of penicillin $\mathrm{G}$ degradation is higher at $10 \mathrm{mAcm}^{-2}$ and around 1.6 $\mathrm{Ah} \mathrm{dm}^{-3}$ are required to attain the complete removal of 
penicillin G (vs. $2.6 \mathrm{Ah} \mathrm{dm}^{-3}$ required when working at $100 \mathrm{~mA} \mathrm{~cm}^{-2}$ ). Additionally, paying attention to the kinetic constant shown in onsets of Figure 1, it can be observed that chloride media attains the highest antibiotic removal rate at $100 \mathrm{~mA} \mathrm{~cm}^{-2}\left(\mathrm{k}: 2.334 \mathrm{~min}^{-1}\right)$. Likewise, the removal rate of penicillin $\mathrm{G}$ in sulfate media is also faster than in urine media. In this case, and in contrast with those observed in chloride and sulfate media, kinetic constants are not almost influenced by current density: 0.014 and $0.010 \mathrm{~min}^{-1}$ for electrolysis at 10 and $100 \mathrm{~mA} \mathrm{~cm}^{-2}$, respectively. This is an unexpected behavior taking into account that high current densities favor the production of large amounts of hydroxyl radicals [Equation (7)] that promote both the organic oxidation and the formation of oxidants according to Equations (8)-(11).[12] However, as previously commented, these species could be destroyed during the treatment or be wasted in the oxidation of other organics such as urea, creatinine or uric acid, decreasing the removal rate of the antibiotic in urine media at $100 \mathrm{mAcm}^{-2}$.

$$
\begin{aligned}
& \mathrm{H}_{2} \mathrm{O} \rightarrow{ }^{\cdot} \mathrm{OH}+\mathrm{H}^{+}+\mathrm{e}^{-} \\
& \mathrm{Cl}^{-}+{ }^{\cdot} \mathrm{OH} \rightarrow \mathrm{ClO}^{-}+\mathrm{H}^{+}+\mathrm{e}^{-} \\
& 2 \mathrm{SO}_{4}{ }^{2-}+\cdot \mathrm{OH} \rightarrow \mathrm{S}_{2} \mathrm{O}_{8}{ }^{2-}+\mathrm{OH}^{-}+\mathrm{e}^{-} \\
& 2 \mathrm{PO}_{4}{ }^{3-}+{ }^{\circ} \mathrm{OH} \rightarrow \mathrm{P}_{2} \mathrm{O}_{8}{ }^{4-}+\mathrm{OH}^{-}+\mathrm{e}^{-} \\
& 2 \mathrm{CO}_{3}{ }^{2-}+{ }^{\circ} \mathrm{OH} \rightarrow \mathrm{C}_{2} \mathrm{O}_{6}{ }^{2-}+\mathrm{OH}^{-}+\mathrm{e}^{-}
\end{aligned}
$$

To confirm this, Figure 3 shows the oxidants electrogenerated as function of the applied electric charge during the electrolysis process. Here, it is important to notice that oxidants measured are not the total oxidants electrogenerated during the electrolysis process but those oxidants that have not chemically reacted with other species in solution.

The non-reacted oxidants monitored are observed to be significantly influenced by current density and water matrix. As expected, the higher the current density the higher the amount of oxidants accumulated in the reaction system. Likewise, as it can be noticed in the onset of the figures, during the first stages of the process, when penicillin $\mathrm{G}$ is in the solution, the amount of oxidants detected is low and their concentration starts to increase from around $2.5 \mathrm{Ah} \mathrm{dm}^{-3}$, once penicillin G has been almost removed from the solutions. From this point, the differences observed among the three-supporting media are more relevant. Sulfate and urine media show a similar behavior, while the concentration of chloro-species increases and then decreases abruptly. As it is known, hypochlorite formed in chloride media [Eqs. (1) and (2), or Eq. (8)] can be further oxidized to other chlorine compounds in higher oxidation state such as chlorate and perchlorate [Equations (12)-(14)], and these species are not quantified by this titration technique $\left(\mathrm{I}^{-} / \mathrm{I}_{2}\right.$ method). In these tests, chlorate and perchlorate formation were monitored and quantified by ion chromatography. The maximum concentration achieved of chlorate and perchlorate was 659.91 and $666.35 \mathrm{mgCldm}^{-3}$ at $10 \mathrm{mAcm}^{-2}$ and, 271.06 and $1053.32 \mathrm{mgCldm}^{-3}$ at $100 \mathrm{~mA} \mathrm{~cm}^{-2}$, respectively, at the end of the treatment.
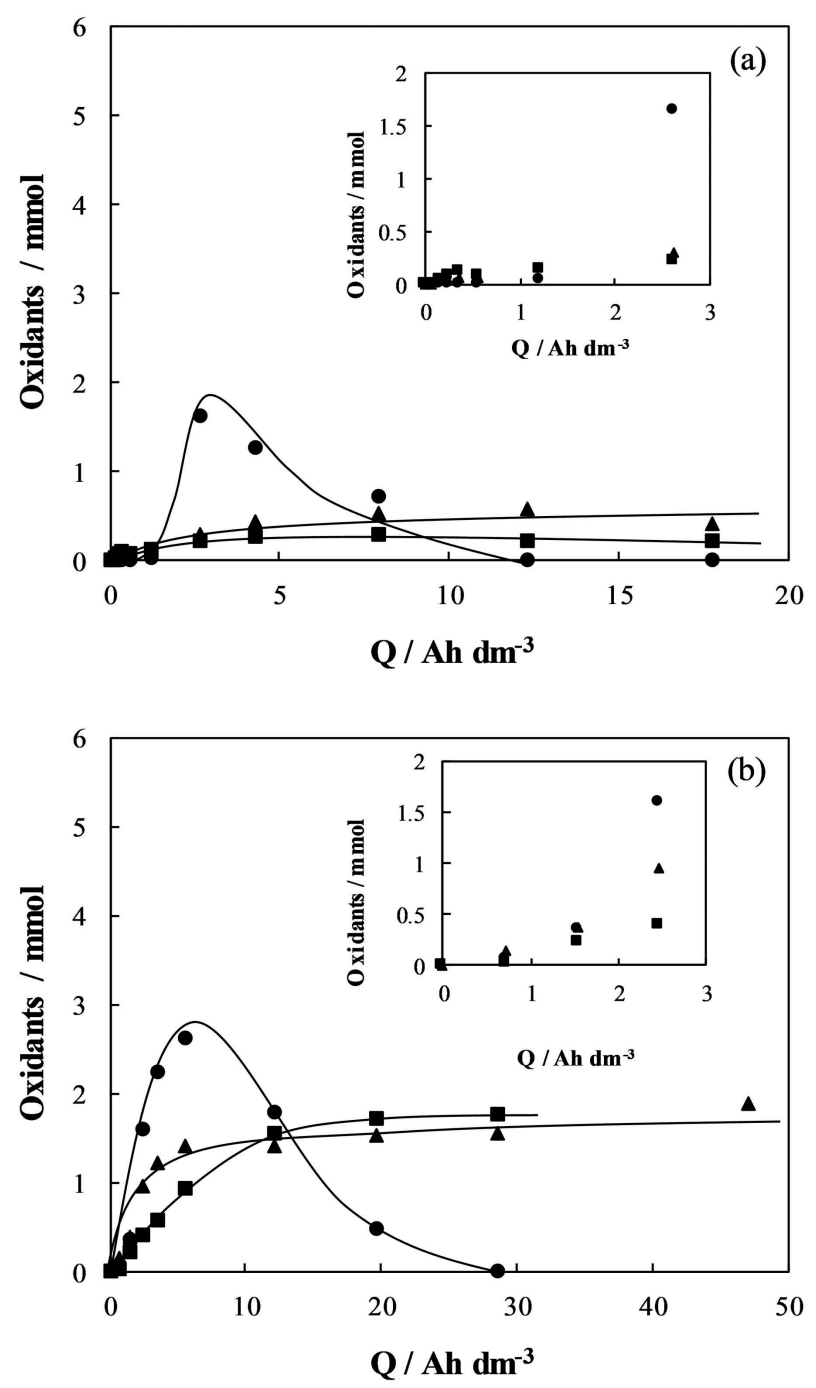

Figure 3. Influence of current density on oxidants electrogenerated as function of the applied electric charge during the electrolysis of $100 \mathrm{mg} \mathrm{dm}^{-3}$ penicillin $\mathrm{G}$ with diamond anodes. (口) $2000 \mathrm{mg} \mathrm{dm}^{-3} \mathrm{Na}_{2} \mathrm{SO}_{4}$; (O) $2000 \mathrm{mg} \mathrm{dm}^{-3} \mathrm{NaCl}$; (A) urine. (a) $10 \mathrm{~mA} \mathrm{~cm}^{-2}$; (b) $100 \mathrm{~mA} \mathrm{~cm}^{-2}$.

However, in the moment in which the antibiotic was completely removed only $2.96 \%$ and $0.13 \%$ of these values were reached at $10 \mathrm{mAcm}^{-2}$ for chlorate and perchlorate, respectively, and slightly higher values were obtained at $100 \mathrm{mAcm}^{-2}(17.62 \%$ and $3.81 \%$, respectively), indicating a much less important problem, in particular when operating at the lowest current intensity, in which the problem can be considered as almost negligible.

At this point, it is important to highlight that synthetic urine also presents a significant concentration of chlorides in its composition $\left(475.52 \mathrm{mg} \mathrm{dm}^{-3}\right.$ ) but the trend observed in the oxidation concentration is softer. In this case, hypochlorite may be further oxidized to chlorate and perchlorate, but it can also react with other oxidants electrogenerated in the system. In any case, these high-oxidized-chloro species are hazardous, and they do not contribute to the degradation of pollutants under the experimental conditions tested (room temperature). ${ }^{[14,22 b]}$ Concentrations of chlorates and perchlorate measured in the 
moment in which the antibiotic is completely removed were 3.14 and $0 \mathrm{mgCldm}^{-3}$ at $10 \mathrm{mAcm}^{-2}$ and, 16.99 and $8.01 \mathrm{mgCldm}^{-3}$ at $100 \mathrm{mAcm}^{-2}$, respectively, at the end of the treatment, pointing out a considerably smaller problem in those conditions.

$$
\begin{aligned}
& \mathrm{ClO}^{-}+{ }^{\cdot} \mathrm{OH} \rightarrow \mathrm{ClO}_{2}^{-}+\mathrm{H}^{+}+\mathrm{e}^{-} \\
& \mathrm{ClO}_{2}{ }^{-}+{ }^{\cdot} \mathrm{OH} \rightarrow \mathrm{ClO}_{3}{ }^{-}+\mathrm{H}^{+}+\mathrm{e}^{-} \\
& \mathrm{ClO}_{3}{ }^{-}+{ }^{\cdot} \mathrm{OH} \rightarrow \mathrm{ClO}_{4}{ }^{-}+\mathrm{H}^{+}+\mathrm{e}^{-}
\end{aligned}
$$

Figure 4 shows the influence of the current density on the mineralization efficiency for the complete removal of $100 \mathrm{mg} \mathrm{dm}^{-3}$ penicillin $\mathrm{G}$ during the electrolysis with diamond anodes. The mineralization efficiency $(\eta)$ was calculated accord-

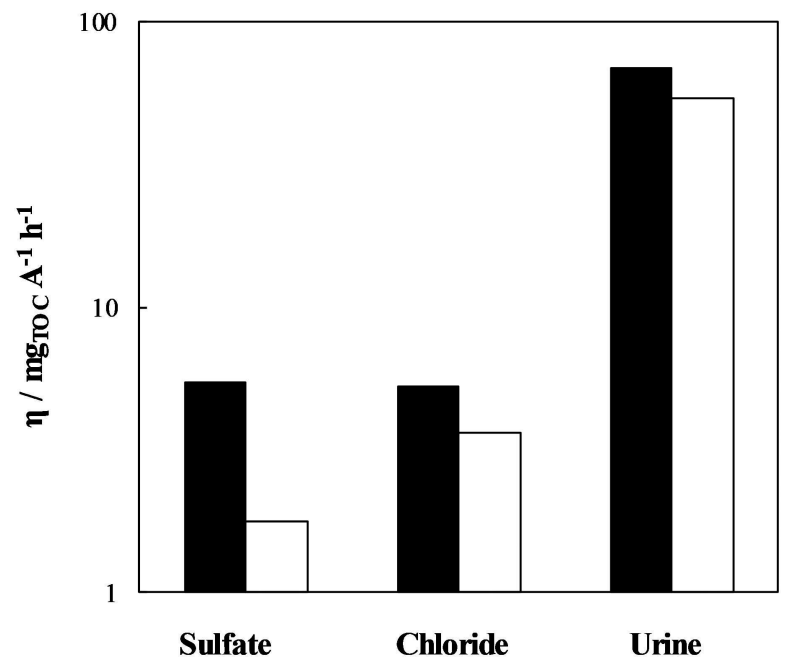

Figure 4. Influence of the current density on the mineralization efficiency reached for the complete removal of $100 \mathrm{mg} \mathrm{dm}^{-3}$ penicillin $\mathrm{G}$ by electrolysis with diamond anodes. (口) $10 \mathrm{~mA} \mathrm{~cm}^{-2}$; ( $\left.\square\right) 100 \mathrm{~mA} \mathrm{~cm}^{-2}$.

ing to Equation (15), from the ratio between the variation of the TOC concentration and the applied electric charge $\left(Q_{i}\right)$ for which the complete removal of an initial concentration of $100 \mathrm{mg} \mathrm{dm}^{-3}$ penicillin $\mathrm{G}$ is attained. ${ }^{[25]}$

$\eta\left(\mathrm{mg}_{\mathrm{TOC}} \mathrm{A}^{-1} \mathrm{~h}^{-1}\right)=\frac{\mathrm{TOC}_{\mathrm{o}}\left(\mathrm{mg} \mathrm{dm} \mathrm{d}^{-3}\right) \cdot \mathrm{TOC}_{\mathrm{Q}_{\mathrm{i}}}\left(\mathrm{mg} \mathrm{dm}^{-3}\right)}{\mathrm{Q}_{\mathrm{i}}\left(\mathrm{Ah} \mathrm{dm}^{-3}\right)}$

As expected, the mineralization efficiency for the complete removal of penicillin $\mathrm{G}$ is higher at lower current density values for all the water matrix tested. Specifically, sulfate and chloride media lead to 5.5 and $5.3 \mathrm{mg}_{\text {TOC }} A^{-1} h^{-1}$, respectively, whereas $68.8 \mathrm{mg}_{\text {то }} A^{-1} h^{-1}$ is attained with urine media. These results suggest that the cocktail of powerful oxidants generated during the treatment of urine polluted with penicillin $G$ favors the complete mineralization of the organic matter present in the effluent.

Once electrolysis with diamond anodes has been proven efficient for the removal of antibiotic penicillin $G$ in different water matrices, the influence of the anode material was assessed. To do this, a metal mixed oxide (MMO) electrode was employed for the treatment of synthetic urine polluted with penicillin G. This study was only carried out in this media, in order to evaluate if it is possible to reduce the danger of the urine by removing the antibiotic and avoiding the formation of chlorine compounds in high oxidation state. In addition, it was aimed to see if the selective degradation of the antibiotic is improved with the use of the MMO electrodes, as compared to the results obtained with the diamond coatings. Figure 5
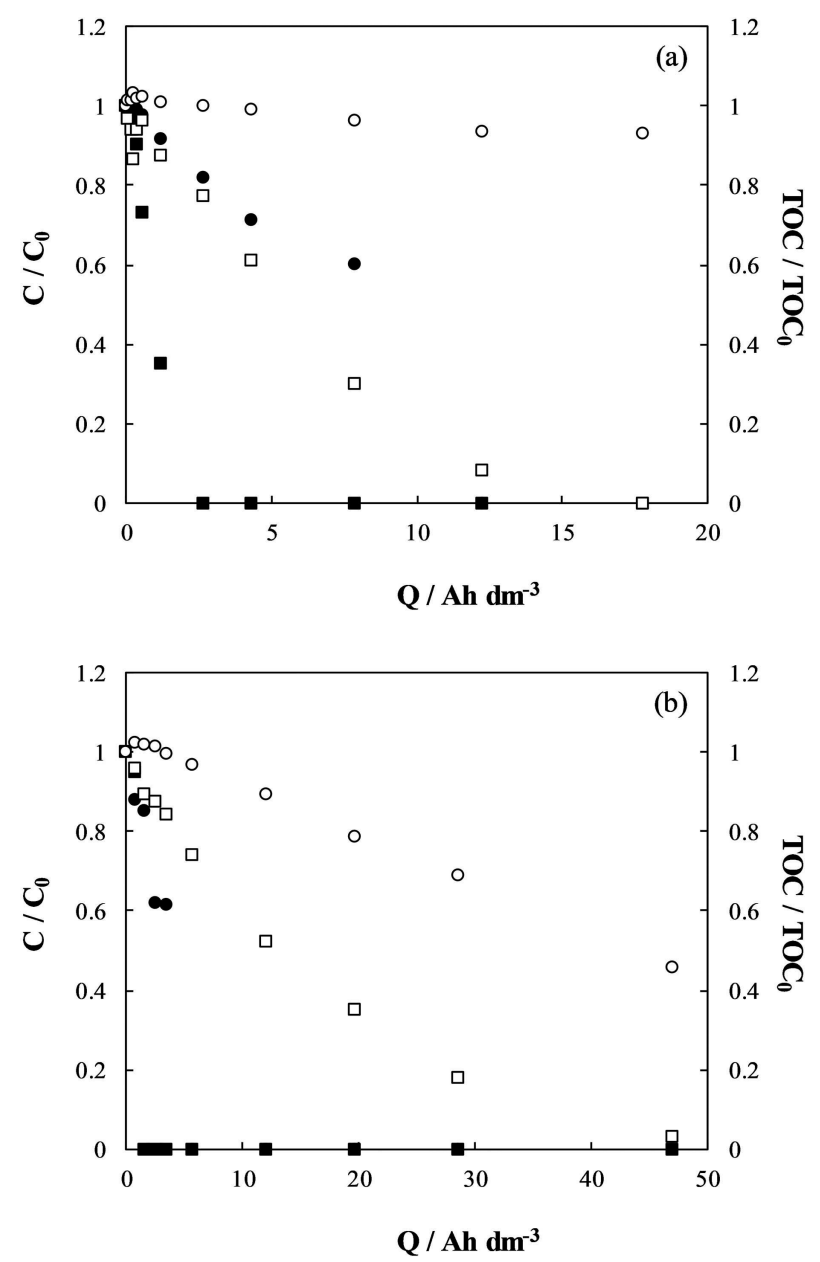

Figure 5. Influence of current density on penicillin G concentration (full symbols) and TOC (empty symbols) as function of the applied electric charge during the electrolysis of synthetic urine. ( $\square$ ) BDD; (O) MMO. (a) $10 \mathrm{mAcm}^{-2}$; (b) $100 \mathrm{mAcm}^{-2}$.

compares the evolution of the antibiotic and TOC with the applied electric charge during the electrolysis at different current densities using BDD and MMO anodes.

As can be observed, penicillin $G$ is totally removed under the experimental conditions studied, although its removal depends noteworthy on both anode materials and current density values. It is well known that BDD and MMO materials present different electrocatalytic properties, which strongly affect both the selectivity and the efficiency of the oxidation process. These electrocatalytic properties are related to the 

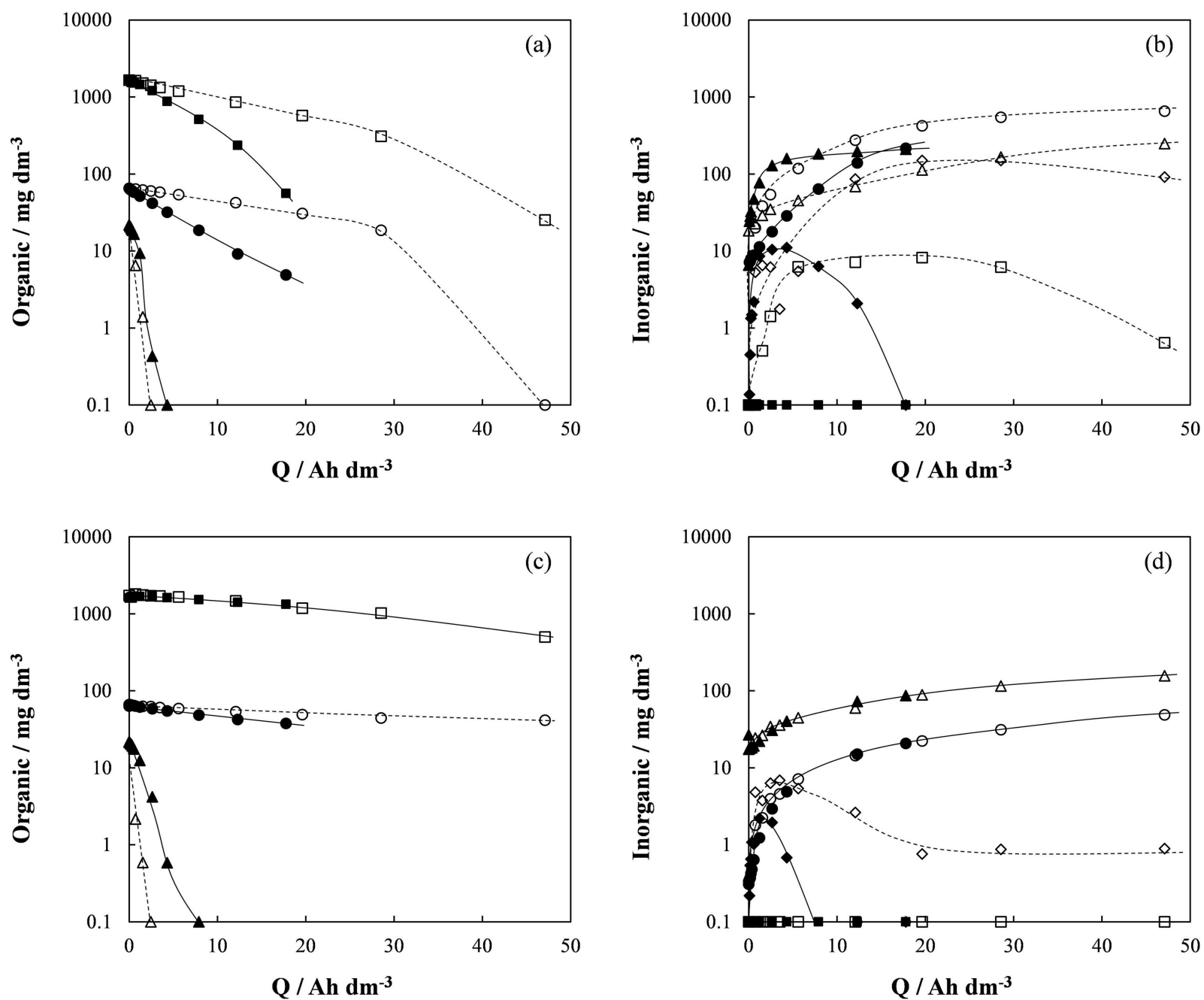

Figure 6. Influence of the anode material on the evolution of nitrogen species as function of the applied electric charge during the electrolysis of

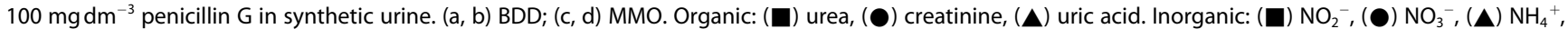
$(\diamond) \mathrm{NH}_{\mathrm{x}} \mathrm{Cl}_{\mathrm{y}}$. Full symbols: $10 \mathrm{mAcm}^{-2}$; empty symbols: $100 \mathrm{mAcm}^{-2}$.

strong/weak interaction between electrode $(M)$ and hydroxyl radicals $\left({ }^{\circ} \mathrm{OH}\right)$ from water oxidation. Thus, BDD is considered a non-active electrode where hydroxyl radicals are physisorbed on the electrode surface (weak interaction) whereas MMO is reported an active one as hydroxyl radicals are chemisorbed on the electrode surface (strong interaction). Then, the weaker the $\mathrm{M}\left({ }^{\circ} \mathrm{OH}\right)$ interaction the higher its efficiency for the oxidation of organics. ${ }^{[26]}$ This may explain the experimental results obtained: BDD anode yields a more efficient removal of penicillin $G$ than MMO anode during electrolysis at $10 \mathrm{~mA} \mathrm{~cm}^{-2}$. That is, to attain the complete removal of penicillin $2.6 \mathrm{Ahdm}^{-3}$ or $12.3 \mathrm{Ah} \mathrm{dm}^{-3}$ should be applied in case of using BDD or MMO, respectively. Same behavior is obtained operating at higher current density. Thus, penicillin $\mathrm{G}$ is completely removed at $1.54 \mathrm{Ah} \mathrm{dm}^{-3}$ and 5.61 $\mathrm{Ah} \mathrm{dm}^{-3}$ with BDD and MMO at $100 \mathrm{mAcm}^{-2}$. Again, the BDD is more efficient and the application of higher current densities lead to a more efficient removal of the pharmaceutical compound.

With the MMO electrode the concentrations of chlorate and perchlorate formed were much lower than with the BDD. Thus, in the moment in which the penicillin $G$ is removed only 0.41 and $5.08 \mathrm{mgCldm}^{-3}$ were formed of chlorates at 10 and $100 \mathrm{~mA} \mathrm{~cm}^{-2}$, respectively. In addition, no perchlorate was formed in any of the tests. These results are very positive in view of a potential applicability of the technology at the full scale, because they are related to the main drawback of the technology. Likewise, the selective oxidation of organics is quite similar with MMO as compared with the BDD anode. When the penicillin $\mathrm{G}$ is completely depleted no uric acid was removed, neither at 10 nor at $100 \mathrm{mAcm}^{-2}$. Regarding creatinine the percentages of removal increase up to 64.36 and $93.11 \%$, respectively, also indicating that the oxidation of the antibiotic is much more important. Opposite, lower differences can be found between the oxidazability of urea (as it was also shown with BDD) because the percentages or removal increases up to 88.40 and $96.00 \%$ at 10 nor at $100 \mathrm{~mA} \mathrm{~cm}^{-2}$, respectively. Thus, it can be obtained a partially selective removal of the penicillin $\mathrm{G}$, which opens the possibility of designing new combined processes. 
Regarding mineralization (complete treatment by electrolysis), BDD anode yields an almost complete mineralization (96.9\% TOC removal) at $47.1 \mathrm{Ah} \mathrm{dm}^{-3}$ for a current density of $100 \mathrm{~mA} \mathrm{~cm}^{-2}$ whereas it reaches a total mineralization at 17.8 $\mathrm{Ah} \mathrm{dm}^{-3}$ for a current density of $10 \mathrm{mAcm}^{-2}$. However, MMO anode only attains 7.0 and $54.1 \%$ TOC removal during electrolysis at 10 and $100 \mathrm{mAcm}^{-2}$, respectively. This fact may be explained not only considering the removal of the antibiotic Penicillin G, but also the simultaneous degradation of other organics presented in urine media. Thus, Figure 6 shows the influence of anode material on the removal of urea, creatinine and uric acid and likewise, it is shown the evolution of other inorganic nitrogen species in solution.

On the one hand, a complete removal of uric acid is observed, regardless the anode material used and, unexpectedly, its degradation is more efficient at the highest current density. Otherwise, the removal of both urea and creatinine presents a similar behaviour. BDD anode yields a more efficient removal than $\mathrm{MMO}$ anode and as expected, the lower current density the higher removal efficiency. Thus, a complete mineralization for urea and creatinine is only attained below $50 \mathrm{Ah} \mathrm{dm}^{-3}$ at $100 \mathrm{~mA} \mathrm{~cm}^{-2}$ during electrolysis with BDD anode. However, it is noteworthy that urea removal efficiency is not influenced by current density when working with $\mathrm{MMO}$ anode. Current charges required for mineralization are more than 1 log unit above the required for the removal of the antibiotic and they support the necessity and potentiality of combined treatments.

Regarding the evolution of inorganic nitrogen species, nitrates and ammonium ions are observed to act as final reaction products whereas nitrites and chloramines behave as intermediate ones. In fact, as reported in literature, nitrite is the key specie for the reduction of nitrate to ammonium ions. ${ }^{[27]}$ Regarding chloramines, they are formed by the reaction between hypochlorite and ammonium (break point reaction). Then, its formation depends on the hypochlorite generated and the amount of ammonium available in the reaction system. Thus, the higher concentration detected during MMO-electrolysis may be related to higher concentration of hypochlorite electrogenerated in this case. As it is known, the further oxidation of hypochlorite to chlorate and perchlorate is not favoured with this anode material and then, it can react with ammonium to form chloramines. Figure 7 shows the maximum concentration of oxidants measured as well as the profile of chlorate and perchlorate detected in both electrolytic systems. In terms of overall oxidant concentration, it is two times higher in BDD-electrolysis than in MMO ones, regardless current density studied. Regarding highly oxidized chloro species, large amounts of chlorates and perchlorates are produced during electrolysis with BDD anodes. As reported in literature, ${ }^{[13 \mathrm{~b}]}$ this behavior is explained by the large concentration of hydroxyl radicals produced from water oxidation (equation 7) which react with chlorine to lead to the final formation of perchlorates at high current densities (equations $8 ; 12-14$ ). ${ }^{[28]}$ On the other hand, perchlorate is not detected during MMO-electrolysis and only chlorate starts to be formed after passing more than $20 \mathrm{Ahdm}^{-3}$. That is, once penicillin has been completely
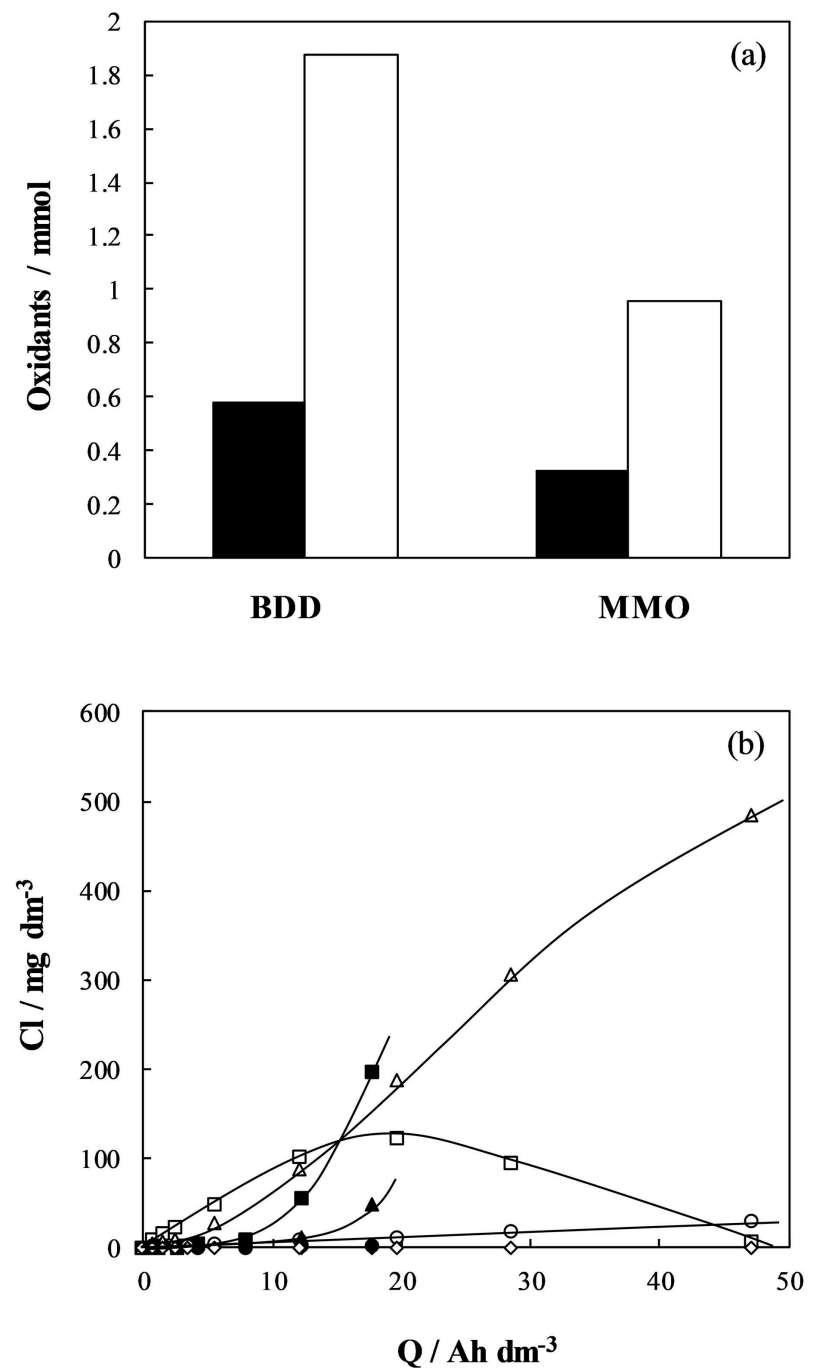

Figure 7. a) Maximum concentration of oxidants electrogenerated during the electrolysis of synthetic urine polluted with $100 \mathrm{mg} \mathrm{dm}^{-3}$ penicillin $\mathrm{G}$. b) Chlorine speciation as function of the applied electric charge during the electrolysis of synthetic urine polluted with $100 \mathrm{mgdm}^{-3}$ penicillin $\mathrm{G}$. ( $\mathrm{Cl}-\mathrm{ClO}_{3}{ }^{-} \mathrm{BDD} ;(\mathbf{C l})-\mathrm{ClO}_{3}{ }^{-} \mathrm{MMO} ;(\boldsymbol{\Delta}) \mathrm{Cl}-\mathrm{ClO}_{4}{ }^{-} \mathrm{BDD} ;(\bullet) \mathrm{Cl}-\mathrm{ClO}_{4}^{-} \mathrm{MMO}$. Full bars/symbols: $10 \mathrm{~mA} \mathrm{~cm}^{-2}$; empty bars/symbols: $100 \mathrm{~mA} \mathrm{~cm}^{-2}$.

degraded (12.3 or $5.6 \mathrm{Ah} \mathrm{dm}^{-3}$ at $10 \mathrm{mAcm}^{-2}$ and $100 \mathrm{mAcm}^{-2}$, respectively.

In summary, the target pollutant penicillin $G$ is selectively removed by electrolysis in urine media, regardless both current density and anode material studied. However, it is noteworthy that the anode material significantly influences the mineralization process. Then, electrolysis with $\mathrm{MMO}$ anodes lead to a selective degradation of the target compound without attending the complete mineralization of the studied effluent. This seems to indicate that this technology could be used as a pretreatment for a later disposal of this effluent into the entrance of an urban wastewater treatment plant (UWWTP). Here, it should be previously necessary to examine biodegradability and toxicity parameters of the pre-treated effluent in order to check its acquisition of similar physical-chemical characteristics than urban effluents. ${ }^{[29]}$ 


\section{Conclusions}

From this work, the following conclusions can be drawn:

- Electrolysis with BDD anodes allows a complete removal of penicillin $G$, being this removal the most efficient at the highest current density due to the largest concentration of oxidants electrogenerated. Likewise, water matrix significantly influences on the penicillin $G$ removal at the lowest current density within the following order of efficiency: chloride $>$ sulfate $>$ urine media.

- The total mineralization of synthetic effluents can be obtained by electrolysis using BDD anodes in urine media at the lowest current density with a mineralization efficiency of $68.8 \mathrm{mg}_{\text {ToC }} A^{-1} h^{-1}$, even though initial TOC concentration is 15 times higher than in sulfate or chloride media.

- Electrolysis with MMO anodes in urine media also allows a complete removal of penicillin $\mathrm{G}$ although this removal is less efficient than using BDD anodes. In addition, mineralization process is only achieved up to $7.0 \%$ at the lowest current density due to different electrocatalytic characteristics.

- Chlorates and perchlorates are produced during electrolysis with BDD anodes whereas only chlorates are detected when using $\mathrm{MMO}$ anodes. However, the presence of these chlorine species is almost negligible below applied electric charge values for which penicillin $G$ is totally removed.

- There is a selective oxidation of penicillin $G$ as compared to that of the other organics contained in urine. By providing only the electric charge required for the depletion of the antibiotic, an effluent with a very significant concentration of the other organics and a negligible concentration of chlorate can be obtained, in particular when operating at low current densities.

\section{Acknowledgements}

The authors acknowledge funding support from Junta de Comunidades de Castilla-La Mancha (JCCM) and European Union (EU, FEDER) through the project SBPLY/17/180501/000396, and from Spanish Ministry of Economy, Industry and Competitiveness and European Union through the project UNCM15-CE-3385. Additionally, authors also acknowledge funding support from Junta de Comunidades de Castilla-La Mancha (JCCM) through the grants SBPLY/16/180501/000404 (Dr. Salvador Cotillas) and SBPLY/18/180501/000009 (Miguel Herraiz). UCLM-Excma. Diputación de Albacete (Apoyo a la actividad investigadora en el campus de Albacete) is also acknowledged.

\section{Conflict of Interest}

The authors declare no conflict of interest.

Keywords: diamond coating - electrolysis - mixed metal oxide anode $\cdot$ penicillin $\mathrm{G} \cdot$ urine
[1] a) J. F. Pérez, J. Llanos, C. Sáez, C. López, P. Cañizares, M. A. Rodrigo, J. Environ. Manage. 2017, 195, 216-223; b) M. Fernández, M. Fernández, A. Laca, A. Laca, M. Díaz, J. Environ. Chem. Eng. 2014, 2, 495-502; c) D. P. Mohapatra, S. K. Brar, R. D. Tyagi, P. Picard, R. Y. Surampalli, Sci. Total Environ. 2014, 470-471, 58-75; d) M. I. Badawy, R. A. Wahaab, A. S. ElKalliny, J. Hazard. Mater. 2009, 167, 567-574.

[2] a) K. D. Brown, J. Kulis, B. Thomson, T. H. Chapman, D. B. Mawhinney, Sci. Total Environ. 2006, 366, 772-783; b) M. Ferdig, A. Kaleta, W. Buchberger, J. Sep. Sci. 2005, 28, 1448-1456; c) I. A. Balcioglu, M. Ötker, Turk. J. Eng. Environ. Sci. 2004, 28, 325-331.

[3] a) P. Verlicchi, A. Galletti, M. Petrovic, D. Barceló, J. Hydrol. 2010, 389, 416-428; b) P. Verlicchi, M. Al Aukidy, E. Zambello, Sci. Total Environ. 2015, 514, 467-491.

[4] a) M. Al Aukidy, P. Verlicchi, N. Voulvoulis, Sci. Total Environ. 2014, 493, 54-64; b) P. K. Jjemba, Ecotoxicol. Environ. Saf. 2006, 63, 113-130.

[5] a) M. I. Page, Acc. Chem. Res. 1984, 17, 144-151; b) J. Chen, P. Sun, X. Zhou, Y. Zhang, C. H. Huang, Environ. Sci. Technol. 2015, 49, 4218-4225.

[6] a) X. Zhou, D. Liu, Y. Zhang, J. Chen, H. Chu, Y. Qian, Chem. Eng. J. 2018, 341, 93-101; b) Y. F. Qi, S. B. He, S. Q. Wu, B. B. Dai, C. H. Hu, Desalin. Water Treat. 2015, 55, 1480-1487; c) S. Deng, X. Ma, M. Sun, D. Wei, E. Su, Catal. Commun. 2016, 79, 31-34; d) F. Aldeek, D. Canzani, M. Standland, M. R. Crosswhite, W. Hammack, G. Gerard, J. M. Cook, J. Agric. Food Chem. 2016, 64, 6100-6107.

[7] a) S. Norzaee, M. Taghavi, B. Djahed, F. Kord Mostafapour, J. Environ. Manage. 2018, 215, 316-323; b) J. Chen, C. Fang, W. Xia, T. Huang, C.-H. Huang, Environ. Sci. Technol. 2018, 52, 1461-1470.

[8] a) J. Chen, Y. Wang, Y. Qian, T. Huang, J. Hazard. Mater. 2017, 335, 117 124; b) S. Rahdar, C. A. Igwegbe, A. Rahdar, S. Ahmadi, Desalin. Water Treat. 2018, 106, 330-335; c) H. R. Pouretedal, N. Sadegh, J. Water Proc. Eng. 2014, 1, 64-73.

[9] a) I. Oller, S. Malato, J. A. Sánchez-Pérez, Sci. Total Environ. 2011, 409, 4141-4166; b) I. Sirés, E. Brillas, Environ. Int. 2012, 40, 212-229; c) E. S. Elmolla, M. Chaudhuri, J. Hazard. Mater. 2009, 172, 1476-1481.

[10] a) M. A. Oturan, P. V. Nidheesh, M. Zhou, Chemosphere 2018, 209, 17-19; b) S. Z. J. Zaidi, C. Harito, F. C. Walsh, C. Ponce de León, J. Solid State Electrochem. 2018, 22, 2889-2900; c) E. M. S. Oliveira, F. R. Silva, C. C. O. Morais, T. M. B. F. Oliveira, C. A. Martínez-Huitle, A. J. Motheo, C. C. Albuquerque, S. S. L. Castro, Chemosphere 2018, 201, 740-748; d) S. Cotillas, E. Lacasa, C. Sáez, P. Cañizares, M. A. Rodrigo, Chem. Eng. J. 2018, 331, 606-614; e) D. Dionisio, A. J. Motheo, C. Sáez, M. A. Rodrigo, Sep. Purif. Technol. 2019, 208, 201-207.

[11] S. Dbira, N. Bensalah, A. Bedoui, P. Cañizares, M. A. Rodrigo, Environ. Sci. Pollut. Res. 2015, 22, 6176-6184.

[12] a) C. A. Martínez-Huitle, M. A. Rodrigo, I. Sirés, O. Scialdone, Chem. Rev. 2015, 115, 13362-13407; b) C. A. Martínez-Huitle, M. Panizza, Curr. Opin. Electrochem. 2018, 11, 62-71.

[13] a) P. Cañizares, C. Sáez, A. Sánchez-Carretero, M. A. Rodrigo, J. Appl. Electrochem. 2009, 39, 2143-2149; b) A. Sánchez-Carretero, C. Sáez, P. Cañizares, M. A. Rodrigo, in Synthetic Diamond Films: Preparation, Electrochemistry, Characterization, and Applications, John Wiley and Sons, 2011, pp. 281-310; c) S. Cotillas, A. Sánchez-Carretero, P. Cañizares, C. Sáez, M. A. Rodrigo, Ind. Eng. Chem. Res. 2011, 50, 1088910893; d) J. M. Monteagudo, A. Durán, J. Latorre, A. J. Expósito, J. Hazard. Mater. 2016, 306, 77-86; e) M. E. H. Bergmann, J. Rollin, T. lourtchouk, Electrochim. Acta 2009, 54, 2102-2107.

[14] S. Cotillas, L. Cañizares, M. Muñoz, C. Sáez, P. Cañizares, M. A. Rodrigo, Electrochim. Acta 2017, 246, 372-379.

[15] S. Cotillas, E. Lacasa, C. Sáez, P. Cañizares, M. A. Rodrigo, Water Res. 2018, 128, 383-392.

[16] P. Cañizares, M. Díaz, J. A. Domínguez, J. García-Gómez, M. A. Rodrigo, Ind. Eng. Chem. Res. 2002, 41, 4187-4194.

[17] G. W. Watt, J. D. Chrisp, Anal. Chem. 1954, 26, 452-453.

[18] a) A. v. Wilpert, Z. Anal. Chem. 1957, 155, 378-378; b) H. Freytag, Z. Anal. Chem. 1959, 171, 458-458.

[19] I. M. Kolthoff, E. M. Carr, Anal. Chem. 1953, 25, 298-301.

[20] P. Cañizares, C. Sáez, J. Lobato, R. Paz, M. A. Rodrigo, J. Electrochem. Soc. 2007, 154, E37-E44.

[21] S. Cotillas, E. Lacasa, C. Sáez, P. Cañizares, M. A. Rodrigo, Chem. Eng. J. 2018, 331, 606-614.

[22] a) H. Rubí-Juárez, S. Cotillas, C. Sáez, P. Cañizares, C. Barrera-Díaz, M. A. Rodrigo, Appl. Catal. B 2016, 188, 305-312; b) Y. Lan, C. Coetsier, C. Causserand, K. Groenen Serrano, Electrochim. Acta 2017, 231, 309-318.

[23] M. Panizza, G. Cerisola, Chem. Rev. 2009, 109, 6541-6569.

[24] S. Cotillas, D. Clematis, P. Cañizares, M. P. Carpanese, M. A. Rodrigo, M. Panizza, Chemosphere 2018, 199, 445-452. 
[25] H. Rubí-Juárez, S. Cotillas, C. Sáez, P. Cañizares, C. Barrera-Díaz, M. A. Rodrigo, Sep. Purif. Technol. 2016, 167, 127-135.

[26] M. A. Q. Alfaro, S. Ferro, C. A. Martínez-Huitle, Y. M. Vong, J. Braz. Chem. Soc. 2006, 17, 227-236.

[27] a) E. Lacasa, P. Cañizares, J. Llanos, M. A. Rodrigo, J. Hazard. Mater. 2012, 213-214, 478-484; b) E. Lacasa, P. Cañizares, J. Llanos, M. A. Rodrigo, Sep. Purif. Technol. 2011, 80, 592-599; c) E. Lacasa, J. Llanos, P. Cañizares, M. A. Rodrigo, Chem. Eng. J. 2012, 184, 66-71.

[28] A. Sánchez-Carretero, C. Sáez, P. Cañizares, M. A. Rodrigo, Chem. Eng. J. 2011, 166, 710-714.
[29] A. M. Polo, M. Tobajas, S. Sanchis, A. F. Mohedano, J. J. Rodríguez, Biodegradation 2011, 22, 751-761.

Manuscript received: November 30, 2018

Revised manuscript received: December 31, 2018

Accepted manuscript online: January 2, 2019 